\title{
Application of Fuzzy MOORA and GRA in Multi-Criterion Decision Making Problems
}

\author{
M. Archana \\ Assistant Professor \\ Dept. of Information Technology \\ GITAM University, Hyderabad campus \\ Hyderabad, Andhra Pradesh, INDIA
}

\author{
V. Sujatha \\ Assistant Professor \\ Dept. of CSE \\ GITAM University, Hyderabad campus \\ Hyderabad, Andhra Pradesh, INDIA
}

\begin{abstract}
The recent trend, wireless communications has became one of the striving areas for the developments of cellular technologies. This is because, many people around the world would like to connect to the other, seamlessly, anytime anywhere. Therefore, the selection of the best network connection becomes crucial with the best quality of service. For that reason the fourth generation heterogeneous wireless networks are been introduced where in the mobile terminals in this network will roll freely across different wireless systems and they continuously will undergo vertical and horizontal handovers. This paper introduces a novel fuzzy multiobjective optimization on the basis of ratio analysis (FMOORA) as an effective methodology in the selection of optimal network that provides a best balance between the performance and energy consumption. The resulted decision was validated for acceptance by the well agreed method gray relational analysis (GRA) in the multi-attribute decision making problems.
\end{abstract}

\section{Keywords}

Vertical Handover, 4G, Wireless Networks, MOORA, GRA

\section{INTRODUCTION}

In recent years, many heterogeneous wireless networks, like wireless metropolitan area networks (WMANs), wireless local area networks (WLANs), cellular networks, Bluetooth, etc, have been extensively used in many communication applications. These wireless technologies when combined with the advanced innovative wireless systems laid the foundation for the IP based $4 \mathrm{G}$ wireless communications to further improve the performance of QoS. These could be heterogeneous with different access technologies which are integrated through a single IP based core. The continuous growth of consumer demand for mobile internet and other broadband services will not be possible through the use of a single mobile technology such as $3 \mathrm{G}$, whereas it is possible with this new wireless network solution i.e. 4G. This network can be accessed from different kinds of terminals and devices with the aid of several architectures and technologies to integrate the performance with the user flexibility. Hence, handling over between different wireless networks appears as one of the key solutions in today's heterogeneous wireless systems. The handovers are classified into two main streams. They are horizontal handover and Vertical handover. When access points using the same wireless technology involved in moving a mobile terminal, is referred as horizontal handover. On the other hand, vertical handover refers to the process of transferring the mobile terminal between access points using different wireless technologies. The Handover technique has four different phases: Handoff Initiation Phase (HIP), System
Discovery Phase (SDP), Handover Decision Phase (HDP), Handoff Execution Phase (HEP). In HIP, the process was modified with the help of some criteria value like signal strength, link quality etc., The SDP helps in deciding its neighbor network which is discovered by the mobile user and exchanges information about QoS offered by these networks. The main phase of the handover process is HDP, where it compares the neighbor network QoS and the mobile users QoS which increases the ease of the decision maker to select the mobile user who have to direct the connection. The last phase HEP, is responsible for establishing the connection and release the connections as well as the invocation of security service. From the above discussion it is evident that the handover process mainly depends on selecting the most energy efficient network. Many investigations have been performed to know about the telecommunications and the handovers. Some of these are:

R. Good et al.[1] considered the case of an integrated IEEE 802.11 and Universal Mobile Telecommunications Standard (UMTS), and proposed the concept of introducing a mechanism which is required to supervise the WLAN and UMTS interfaces, and based on certain criteria switch between the two. Traffic streams are to be cautiously monitored when performing handovers due to the change in bit rate.

Johann Marquez-Barja.et.al[4] bifurcated the vertical handover process into three parts (i) Handover information gathering (ii) Handover decision, and (iii) Handover execution. Wherein, in the first phase the data is gathered to be used and processed for making decisions for the next phase. The next phase that is the HOD is used for making the best selection out of the available networks and the last phase is used for controlling the execution of the Vertical Handover Process to achieve accuracy by taking into account the geographical location, the selected network and the precise time.

Bashar J Hamza.et.al[12],considered the case of minimizing the handover process in various heterogenous wireless networks. He reviewed on different literatures corresponding to hand over process and he came to an conclusion that the stream control transmission protocol is much more robust against the packet loss and the delay compared to the transmission control protocol and the mobile IP.

M. M. A. Khan.et.al[6] considered the case of maintaining dual connections simultaneously which combines our mobile device with multiple transceivers that are capable in maintaining radio links between WiMAX and UMTS networks in parallel resulting in a make-before-break type of handover .

Xiaohuan Yan[9] considered the case of categorizing the vertical handover decision algorithms into four groups i.e RSS based algorithms, Bandwidth based algorithms, Cost 
function based algorithms, Combination algorithms which in turn are used to compute the tradeoffs between the complexity of implementation and efficiency.

Thus, this paper finally focuses on developing a fuzzy multiobjective optimization on the basis of ratio analysis for selection of best network, by taking into considerations of both the user preferences and a number of variant criteria including the QoS requirements of diverse applications.

\section{Fuzzy}

Chen and Hwang have proposed a new concept called FUZZY which are extensively used for handling the fuzziness of the databases. Various fuzzy methods are introduced for this reason so that the problems will be solved that involves fuzzy data. The term Fuzzy Logic defines the state of solving the ill-defined problems by enabling the use of human heuristic knowledge about a given problem. In order to solve the qualitative multicriteria analysis (MA) problems fuzzy pair wise comparison are introduced wherein in the first step the linguistic terms are converted into fuzzy numbers and in the next step the fuzzy numbers are converted into crisp numbers. The former involves a five point scale having the linguistic terms as very low, low, medium, high and very high. This can be shown in the table 1 as:

Table 1: Linguistic Terms

\begin{tabular}{|c|c|}
\hline Linguistic Term & Fuzzy Number \\
\hline Very Low & M1 \\
\hline Low & M2 \\
\hline Average & M3 \\
\hline High & M4 \\
\hline Very High & M5 \\
\hline
\end{tabular}

The later involves the conversion of fuzzy numbers into crisp values and this can be obtained by considering the fuzzy max and fuzzy min and these can be obtained as follows:

$\mu_{\max (\mathrm{x})}=\left\{\begin{array}{l}\mathrm{x}, 0 \leq \mathrm{x} \leq 1 \\ 0, \text { otherwise }\end{array}\right.$

$\mu_{\min (\mathrm{x})}=\left\{\begin{array}{c}1-\mathrm{x}, 0 \leq \mathrm{x} \leq 1 \\ 0, \text { otherwise }\end{array}\right.$

These equations are defined in such a manner that the actual locations of fuzzy numbers can be necessarily coordinated in order to balance the given cases.

The right, left and the total scores are calculated by using the following equations as follows:

$\mu_{\mathrm{L}}\left(\mathrm{M}_{1}\right)=\operatorname{Sup}\left[\mu_{\min (\mathrm{x})}-\mu_{\mathrm{M} 1(\mathrm{x})}\right]$

$\mu_{\mathrm{R}}\left(\mathrm{M}_{1}\right)=\operatorname{SUP}\left[\mu_{\max (\mathrm{x})}-\mu_{\mathrm{M} 1(\mathrm{x})}\right]$

$\mu_{\mathrm{T}}\left(\mathrm{M}_{1}\right)=\left[\mu_{\mathrm{R}(\mathrm{M} 1)+1}-\mu_{\mathrm{l}(\mathrm{M} 1)}\right] / 2$

The conversion of linguistic scores into fuzzy scores for a 5 point scale can be given in the Table 2

Table 2: Fuzzy scores

\begin{tabular}{|c|c|c|}
\hline Linguistic Term & Fuzzy Number & $\begin{array}{c}\text { Crisp } \\
\text { Score }\end{array}$ \\
\hline Very Low & M1 & 0.115 \\
\hline Low & M2 & 0.495 \\
\hline Average & M3 & 0.500 \\
\hline High & M4 & 0.695 \\
\hline Very High & M5 & 0.895 \\
\hline
\end{tabular}

\section{MOORA}

Optimization refers to finding one or more feasible solutions which corresponds to extreme values of one or more objectives. When an optimization problem involves more than one objective function, the task of finding one or more objective functions is known as multi-objective optimization. The MOORA method, first introduced by Brauers (2004) is such a multiobjective optimization technique. The full form of MOORA is Multi-Objective Optimization on the basis of Ratio Analysis .This method mainly focuses on a set of various complex assumptions wherein the best network can be selected through this method by combining it with fuzzy. This method involves the following steps:

Step 1: The prime step is to determine the objective in order to key out the relevant evaluation attributes

Step 2: The next step is to correspond the entire information available for the attributes in the form of a decision matrix. The data can be represented as matrix Xmxn. Where xij is the performance measure of $i^{\text {th }}$ alternative on $j^{\text {th }}$ attribute, $m$ is the number of alternatives, and $\mathrm{n}$ is the number of attributes. A ratio system is established through which every performance of an alternative on an attribute is compared to a denominator which is a representative for all the alternatives concerning that attribute.

$\mathrm{x}=\left[\begin{array}{ccccc}\mathrm{x}_{11} & \mathrm{x}_{12} & \mathrm{x}_{13} & \cdots & \mathrm{x}_{1 \mathrm{n}} \\ & \vdots & & \ddots & \vdots \\ \mathrm{x}_{\mathrm{m} 1} & \mathrm{x}_{\mathrm{m} 2} & \mathrm{x}_{\mathrm{m} 3} & \cdots & \mathrm{x}_{\mathrm{mn}}\end{array}\right]$

Step 3: MOORA method relates to the ratio system, in which the denominator is balanced to the response of an objective for each alternative, and it can be obtained by finding the square root of the sum of squares of each alternative per attribute. This ratio can be expressed as below:

$x_{i j}^{*}=\frac{x_{i j}}{\sqrt{\sum x_{i j}^{2}}}(j=1,2 \ldots ., n) \ldots \ldots .$.

Where $\mathrm{X}_{\mathrm{ij}}$ is a dimension less number which belongs to the interval $[0,1]$ representing the normalized performance of alternative $\mathrm{j}$ on objective $\mathrm{i}$.

Step 4: For multiobjective optimization, these normalized performances are added in case of maximization (for beneficial attributes) and subtracted in case of minimization (for non beneficial attributes). Then the optimization problem becomes:

$\mathrm{y}_{\mathrm{i}=} \sum_{\mathrm{j}=1}^{\mathrm{g}} \mathrm{x}_{\mathrm{ij}-}^{*} \sum_{\mathrm{j}=\mathrm{g}+1}^{\mathrm{n}} \mathrm{x}_{\mathrm{ij}}^{*}$

Where $g$ is the number of attributes to be maximized, $(n-g)$ is the number of attributes to be minimized, and $y_{i}$ is the normalized assessment value of $i^{\text {th }}$ alternative with respect to all the attributes.

Step 5: In many cases, it is commonly observed that few attributes are more important than the others. In order to give more importance to an attribute, it could be multiplied with its corresponding weight (significance coefficient) (Brauers et al. 2009). When these attribute weights are taken into consideration, Eq. 3 becomes as follows:

$$
y_{i}=\sum_{j=1}^{g} w_{j} x_{i j}^{*}-\sum_{j=g+1}^{n} w_{j} x_{i j}^{*}
$$

$(j=1,2 \ldots n) \ldots \ldots \ldots .(5)$

decision matrix Where $\mathrm{Wj}$ is the weight of $\mathrm{j}^{\text {th }}$ attribute, which can be determined applying analytic hierarchy process (AHP) or entropy method. 
Step 6: The $\mathrm{y}_{\mathrm{i}}$ value can be positive or negative depending of the totals of its maxima (beneficial attributes) and minima (non beneficial attributes) in the. An ordinal ranking of $y_{i}$ shows the final preference. Thus, the best alternative has the highest $y_{i}$ value, while the worst alternative has the lowest $y_{i}$ value.

\section{GRA}

The full form of GRA is Gray Relational Analysis, which was proposed by Deng in 1989.This is an impacting measurement method that is used to find the similarity between the series. This mainly comes under the category of data analysis method which mainly relies on the characteristics of the data sequence. This method takes into account the ranking of the relation and establishes the difference in the recent developmental trends among the elements. In this method, the Quantitative analysis is based on the qualitative analysis and is not limited to the distribution of types of raw data. The GRA involves the following steps:

Step 1: Normalize the Matrix:

The Objective function for Maximization is given by

$$
\mathrm{x}_{\mathrm{i}}^{*}(\mathrm{k})=\frac{\mathrm{x}_{\mathrm{i}}^{0}(\mathrm{k})-\min \mathrm{x}_{\mathrm{i}}^{0}(\mathrm{k})}{\max \mathrm{x}_{\mathrm{i}}^{0}(\mathrm{k})-\min \mathrm{x}_{\mathrm{i}}^{0}(\mathrm{k})}
$$

The Objective function for Minimization can be calculated by using the following formulae

$\mathrm{x}_{\mathrm{i}}^{*}(\mathrm{k})=\frac{\max _{\mathrm{i}}^{0}(\mathrm{k})-\mathrm{x}_{\mathrm{i}}^{0}(\mathrm{k})}{\max \mathrm{x}_{\mathrm{i}}^{0}(\mathrm{k})-\min \mathrm{x}_{\mathrm{i}}^{0}(\mathrm{k})}$

Where the reference

factors:

$\mathrm{x}_{0}(\mathrm{k})=\left\{\mathrm{x}_{0}(1), \mathrm{x}_{0}(2), \ldots \ldots \mathrm{x}_{0}(\mathrm{n})\right\}$ and the sequence of compared factors $\mathrm{x}_{\mathrm{i}}(\mathrm{k})=\left\{\mathrm{x}_{\mathrm{i}}(1), \mathrm{x}_{\mathrm{i}}(2), \ldots \ldots \mathrm{x}_{\mathrm{i}}(\mathrm{n})\right\}$ where $\mathrm{i}$ starts from 0 to $\mathrm{n}$ and $\mathrm{x}_{\mathrm{i}}^{*}(\mathrm{k})$ denotes the sequence after the data preprocessing, $\max \mathrm{x}_{\mathrm{i}}^{\mathrm{O}}(\mathrm{k})$ denotes the largest value of $\mathrm{x}_{\mathrm{i}}^{\mathrm{o}}(\mathrm{k}), \min \mathrm{x}_{\mathrm{i}}^{\mathrm{o}}(\mathrm{k})$ denotes the smallest value of $x \operatorname{xio}(\mathrm{k})$, and xo is the desired value.

Step 2: Calculating the gray relational coefficients:

After data preprocessing, the deviation sequence can be calculated as follows:

$$
\begin{aligned}
& \Delta_{0 \mathrm{i}}=\left\|\mathrm{x}_{0}^{*}(\mathrm{k})-\mathrm{x}_{\mathrm{i}}^{*}(\mathrm{k})\right\| \\
& \Delta_{\min }=\underset{\forall \mathrm{j} \in \mathrm{i}}{\min } \min _{\mathrm{k}}\left\|\mathrm{x}_{0}^{*}(\mathrm{k})-\mathrm{x}_{\mathrm{i}}^{*}(\mathrm{k})\right\| \\
& \Delta_{\text {min }}=\max _{\forall \mathrm{j} \in \mathrm{i}} \quad \max _{\forall \mathrm{k}}\left\|\mathrm{x}_{0}^{*}(\mathrm{k})-\mathrm{x}_{\mathrm{j}}^{*}(\mathrm{k})\right\|
\end{aligned}
$$

Whereas $\Delta_{\text {oi }}$ refers to the deviation of sequence between the reference sequence and the comparability sequence, where $0<\xi_{\mathrm{i}}(\mathrm{k}) \leq 1$

After data normalization is carried out, the gray relation coefficient $\xi_{i}(k)$ for the $\mathrm{k}^{\text {th }}$ performance characteristics in the $\mathrm{i}^{\text {th }}$ experiment can be expressed as following

$$
\xi_{\mathrm{i}}(\mathrm{k})=\frac{\Delta_{\min }+\zeta \Delta_{\max }}{\Delta_{0 \mathrm{i}}(\mathrm{k})+\zeta \Delta_{\max }}
$$

Where, $\Delta 0 \mathrm{i}$ is the deviation sequence of the reference sequence and the comparability sequence.

Step 3: Finding the GRC(Gray Relational Code)

The gray relational grade is defined as following:

$$
\gamma_{\mathrm{i}}=\frac{1}{\mathrm{n}} \sum_{\mathrm{k}=1}^{\mathrm{n}} \xi_{\mathrm{i}}(\mathrm{k})
$$

In the real condition of unequal weight being carried by the various factors, then the gray relational grade can be used as:

$$
\gamma_{\mathrm{i}}=\frac{1}{\mathrm{n}} \sum_{\mathrm{k}=1}^{\mathrm{n}} \mathrm{w}_{\mathrm{k}} \xi_{\mathrm{i}}(\mathrm{k}) \quad \sum_{\mathrm{k}=1}^{\mathrm{n}} \mathrm{w}_{\mathrm{k}}=1
$$

Where $\mathrm{W}_{\mathrm{k}}$ denotes the normalized weight of factor $\mathrm{k}$.

\section{Numerical method}

In this paper, we present a simple methodology wherein all the characteristics of a network are given a specific representative values and these are used for simulation through which the QoS requirements and the user requirements tend to fit the situation context. The simulation process has four different advantages: Phonation, Group Discussion, Video streaming, Browser. On the basis of Bandwidth, delay and Energy consumption the selection of the best network depends.

For different advantages and the context the preferences for the user are given much importance and these can be denoted by the linguistic terms. The below table 3 depicts the linguistic assessments denoting the criterion weights for each user profile.

Table 3: Linguistic Assessments

\begin{tabular}{|c|c|c|c|}
\hline User Profile & $\begin{array}{c}\text { Band } \\
\text { width }\end{array}$ & Delay & Consumption \\
\hline Phonation/mobile & L & VH & VH \\
\hline Phonation/home & L & VH & VL \\
\hline $\begin{array}{c}\text { Group Discussion/ } \\
\text { mobile }\end{array}$ & $\mathrm{H}$ & VH & VH \\
\hline $\begin{array}{c}\text { Group } \\
\text { Discussion/home }\end{array}$ & $\mathrm{H}$ & $\mathrm{VH}$ & $\mathrm{L}$ \\
\hline $\begin{array}{c}\text { Video } \\
\text { streaming/mobile }\end{array}$ & $\mathrm{H}$ & $\mathrm{L}$ & $\mathrm{VH}$ \\
\hline $\begin{array}{c}\text { Video } \\
\text { streaming/home }\end{array}$ & $\mathrm{H}$ & $\mathrm{L}$ & $\mathrm{VL}$ \\
\hline Browser/mobile & $\mathrm{L}$ & $\mathrm{L}$ & $\mathrm{VH}$ \\
\hline Browser/home & $\mathrm{L}$ & $\mathrm{L}$ & $\mathrm{VL}$ \\
\hline
\end{tabular}

The Fuzzy Moora method is applied on the above linguistic assessments which results in the ultimate selection of the network

These linguistic terms are then converted to the crisp score in order to determine the criterion. 
Table 4: Crisp Score

\begin{tabular}{|c|c|c|c|}
\hline User Profile & $\begin{array}{c}\text { Band } \\
\text { width }\end{array}$ & Delay & consumption \\
\hline Phonation/mobile & 0.495 & 0.895 & 0.895 \\
\hline Phonation/home & 0.495 & 0.895 & 0.115 \\
\hline $\begin{array}{c}\text { Group } \\
\text { Discussion/mobile }\end{array}$ & 0.695 & 0.895 & 0.895 \\
\hline $\begin{array}{c}\text { Group } \\
\text { Discussion/home }\end{array}$ & 0.695 & 0.895 & 0.495 \\
\hline $\begin{array}{c}\text { video } \\
\text { streaming/mobile }\end{array}$ & 0.695 & 0.495 & 0.895 \\
\hline $\begin{array}{c}\text { video } \\
\text { streaming/home }\end{array}$ & 0.695 & 0.495 & 0.115 \\
\hline Browser/mobile & 0.495 & 0.495 & 0.895 \\
\hline Browser/home & 0.495 & 0.495 & 0.115 \\
\hline \multicolumn{2}{|c|}{} & & \\
\hline
\end{tabular}

The normalized matrix is obtained by the ratio systems in which the square root of the sum of squares of each alternative is to be calculated and is expressed in Table 5:

Table 5: Normalised Matrix

\begin{tabular}{|c|c|c|c|}
\hline User Profile & $\begin{array}{c}\text { Band } \\
\text { width-N }\end{array}$ & Delay & consumption \\
\hline Phonation/mobile & 0.290 & 0.392 & 0.429 \\
\hline Phonation/home & 0.290 & 0.392 & 0.007 \\
\hline $\begin{array}{c}\text { Group } \\
\text { Discussion/mobile }\end{array}$ & 0.407 & 0.392 & 0.429 \\
\hline $\begin{array}{c}\text { Group } \\
\text { Discussion/home }\end{array}$ & 0.407 & 0.392 & 0.131 \\
\hline $\begin{array}{c}\text { video } \\
\text { streaming/mobile }\end{array}$ & 0.407 & 0.120 & 0.429 \\
\hline $\begin{array}{c}\text { video } \\
\text { streaming/home }\end{array}$ & 0.407 & 0.120 & 0.007 \\
\hline Browser/mobile & 0.290 & 0.120 & 0.429 \\
\hline Browser/home & 0.290 & 0.120 & 0.007 \\
\hline \multicolumn{2}{|c|}{} & & \\
\hline
\end{tabular}

The relative normalized weights for each attributes are determined using the AHP method and the weights are as bandwidth $=0.063$, delay $=0.265$ and consumption $=0.672$ and the sum of these criterion weights is equal to one and the consistency ratio is less than 0.1 which is considered as acceptable.

In this paper, we have considered three attributes Bandwidth, Delay and consumption in which two attributes are qualitative and one attribute is quantitative. Hence here bandwidth is considered as non-beneficial attributes and the Delay and consumption are considered as beneficial.

These normalized performances are added in case of maximization (for beneficial attributes) and subtracted in case of minimization (for non-beneficial attributes) by multiplying the corresponding weights for each of the attributes. Then the optimization problem is shown in table 6:
Table 6: MOORA Method

\begin{tabular}{|c|c|c|c|c|c|}
\hline $\begin{array}{c}\text { User } \\
\text { Profile }\end{array}$ & $\begin{array}{c}\text { Band } \\
\text { width }\end{array}$ & Delay & $\begin{array}{c}\text { consum } \\
\text { ption }\end{array}$ & Yi & Rank \\
\hline $\begin{array}{c}\text { Phonation/ } \\
\text { mobile }\end{array}$ & 0.018 & 0.104 & 0.288 & 0.374 & 1 \\
\hline $\begin{array}{c}\text { Phonation/ } \\
\text { home }\end{array}$ & 0.018 & 0.104 & 0.005 & 0.090 & 6 \\
\hline $\begin{array}{c}\text { Group } \\
\text { Discussion } \\
\text { /mobile }\end{array}$ & 0.026 & 0.104 & 0.288 & 0.366 & 2 \\
\hline $\begin{array}{c}\text { Group } \\
\text { Discussion } \\
\text { /home }\end{array}$ & 0.026 & 0.104 & 0.088 & 0.166 & 5 \\
\hline $\begin{array}{c}\text { video } \\
\text { streaming/ } \\
\text { mobile }\end{array}$ & 0.026 & 0.032 & 0.288 & 0.294 & 4 \\
\hline $\begin{array}{c}\text { video } \\
\text { streaming/ } \\
\text { home }\end{array}$ & 0.026 & 0.032 & 0.005 & 0.011 & 8 \\
\hline $\begin{array}{c}\text { Browser/ } \\
\text { mobile }\end{array}$ & 0.018 & 0.032 & 0.288 & 0.302 & 3 \\
\hline $\begin{array}{c}\text { Browser/h } \\
\text { ome }\end{array}$ & 0.018 & 0.032 & 0.005 & 0.018 & 7 \\
\hline
\end{tabular}

Hence, the ranking obtained is as follows: 1-6-2-5-4-8-3-7. This is to be compared to the well agreed algorithm called GRA and we have to prove that in LAN the Phonation/mobile is ranked one in both the methods

Table 7: GRA METHOD

\begin{tabular}{|c|c|c|c|c|c|}
\hline $\begin{array}{c}\text { User } \\
\text { Profile }\end{array}$ & $\begin{array}{c}\text { Ban } \\
\mathbf{d} \\
\text { widt } \\
\mathbf{h}\end{array}$ & Delay & $\begin{array}{c}\text { Consu } \\
\text { mption }\end{array}$ & $\begin{array}{c}\text { Gray } \\
\text { Relational } \\
\text { GRADE }\end{array}$ & $\begin{array}{c}\text { Ran } \\
\mathbf{k}\end{array}$ \\
\hline $\begin{array}{c}\text { Phonation/ } \\
\text { mobile }\end{array}$ & 0 & 0 & 0 & 1 & 1 \\
\hline $\begin{array}{c}\text { Phonation/ } \\
\text { home }\end{array}$ & 0 & 0 & 1 & 0.777778 & 2 \\
\hline $\begin{array}{c}\text { Group } \\
\text { Discussion } \\
/\end{array}$ & 1 & 0 & 0 & 0.777778 & 2 \\
\hline $\begin{array}{c}\text { Group } \\
\text { mobile }\end{array}$ & 1 & 0 & 0.513 & 0.609001 & 3 \\
\hline $\begin{array}{c}\text { Discussion } \\
/\end{array}$ & 1 & 1 & 0 & 0.555556 & 4 \\
\hline $\begin{array}{c}\text { Video } \\
\text { streaming/ } \\
\text { mobile }\end{array}$ & 1 & 1 & 1 & 0.555556 & 4 \\
\hline $\begin{array}{c}\text { Video } \\
\text { streaming/ } \\
\text { home }\end{array}$ & 1 & 1 & 1 & & \\
\hline $\begin{array}{c}\text { Browser/ } \\
\text { mobile }\end{array}$ & 0 & 1 & 0 & 0.777778 & 2 \\
\hline $\begin{array}{c}\text { Browser/ } \\
\text { home }\end{array}$ & 0 & 1 & 1 & & 5 \\
\hline
\end{tabular}

Hence the ranking is as follows: 1-2-2-3-4-5-2-4 


\section{CONCLUSIONS}

The 4G mobile networks can be accessed from different kinds of terminals and devices with the aid of several architectures and technologies to integrate the performance with the user flexibility. Hence, handling over between different wireless networks appears as one of the key solutions in today's heterogeneous wireless systems..This paper proposes a method that takes into account all the requirements including energy consumption, user preferences etc and selects the best one in the LAN network. These user preferences are apprehended through the linguistic assessments and later converted into fuzzy numbers. Taking the LAN network into consideration and applying the MOORA and GRA methods, we came to a conclusion that the phonation/mobile is ranked first in both the methods. The main limitation of the research is that it does not work on the handover triggering process and that this is not tested with all the networks like WIMAX, UMTS, etc. Thus, the future work is based on the designing of the perfect solution for the handover process by taking the network selection method as the important aspect.

\section{ACKNOWLEDGEMENTS}

The author would like to thank to an anonymous referee whose suggestions, for making inferences on the performance of the proposed approach have really added value to this paper in general.

\section{REFERENCES}

[1] "A Multilayered Hybrid Architecture to Support Vertical Handover" between IEEE802.11 and UMTS R. Good rgood@crg.ee.uct.ac.za $\quad$ N. $\quad$ Ventura neco@crg.ee.uct.ac.za

[2] "Requirement of Vertical Handoff Mechanism in 4G Wireless Networks" Mandeep Kaur Gondara1 and Dr. Sanjay Kadam2
[3] "Gray Relational Analysis on the General Budget Revenue of Regional Finance" Rui Zhang 1, Jianming Lin 2, Jichun Peng 2

[4] "An overview of vertical handover techniques: Algorithms, protocols and tools" Johann Marquez-Barja, Carlos T. Calafate, Juan-Carlos Cano, Pietro Manzoni

[5] "The seamless vertical handover between (uiversal mobile telecommunications system) UMTS and (wireless local area network) WLAN by using hybrid scheme of Bi-mSCTP in Mobile IP" Bashar J. Hamza*, Chee Kyun Ng, N. K. Noordin, M. F. A. Rasid, and A. Ismail

[6] "Interworking between WiMAX and UMTS to provide seamless services" M. M. A. Khan*, M. F. B. Ismail and K Dimyati

[7] "Applications of the MOORA method for decision making in manufacturing environment" Shankar Chakraborty

[8] "Robustness of the multiobjective MOORA method with a test for the facilities sector" Willem K. Brauers a \& Edmundas K. Zavadskas b

[9] "A survey of vertical handover decision algorithms in Fourth Generation heterogeneous wireless networks" Xiaohuan Yan a, Y. Ahmet S_ekerciog ${ }^{` l u} a,{ }^{*}$, Sathya Narayanan b

[10] "The MOORA method and its application to privatization in a transition Economy" by Willem Karel M. Brauers1 and Edmundas Kazimieras Zavadskas2

[11] "Regional Development In Lithuania Considering Multiple Objectives By The Moora Method"-Willem Karel M. Brauers1, Romualdas Ginevičius2, Valentinas Podvezko3

[12] "Cross-layer Assisted TCP Algorithms for Vertical Handoff”, Laila Daniel, University of Helsinki Finland 